\title{
Irregular Composites Thermal Establishment for Vibration Control
}

\author{
Nadupuru Bhaskara Rao ${ }^{1}$, Rajesh $\mathrm{CVS}^{2}$, Dommeti Srinivasa Rao ${ }^{3}$ \\ ${ }^{1,2,3}$ Assistant Professor, Mechanical Engineering Department, \\ ${ }^{1,2}$ Vizag Institute of Technology, Visakhapatnam, Andhra Pradesh, India \\ ${ }^{3}$ Avanthi Institute of Engineering and Technology, Vizianagaram, Andhra Pradesh, India
}

\section{ABSTRACT}

The Controlled Behavior Composite Material $(\mathrm{CBCM})$ is a thermal dynamic compound, which has been developed for morphing applications. The thermal establishment is completed by a resource of heating generated within the composite formation. The combination between the induced thermal field and the thermo mechanical properties of the variety of components of the composite formation leads to the transform of the formation shape. The temperature basis is generated by Joule result, Carbon yarns inserted in the composite, are connected to a power supply. The application field of CBCM knowledge is the domain of shape modification and active assembly. The objective of this work is to illustrate the capabilities of CBCM in the domain of vibration control. We will learn some reference plates with special constitution. The influences of these special constitutions, of the CBCM cause and the failure of stiffness for the matrix will be highlighted, for two boundary conditions, free/free and embedded/embedded.

\section{INTRODUCTION}

They are more and more used for technical applications and particularly in the field of controlling structural deformations. In this case, main actuators use piezoelectric and shape memory alloys materials. To make an active composite, these actuators may be used at the scale of the fiber or the matrix, at the scale of the interface between the successive layers in a laminate or at the scale of the linkage between the actuator and a passive composite structure. However, the interface strength between the actuator and the composite plays a crucial role. It is a limit of such a technology for the time life of the structure, especially when the rigidity of the composite structure is high, because to deform the structure the actuator has to fight against this rigidity. For composite structures, the bimetallic strip effect can be obtained by coupling an internal heat source with an unsymmetrical laminate. The particular behavior of the SMA actuators inserted in the composite or fixed on the composite surface, leads to two techniques of vibration control which lead to a frequency shift for different eigenvalue. A CBCM combines these two actions, Lstress field increase and change for the behavior of the matrix, especially a loss of stiffness during heating. In a first par for two kinds of boundary condition, free/free and embedded/embedded and for two CBCM, the influence of the plate rigidity on their dynamical response will be studied: for non activated and activated plates. An embedded/embedded boundary condition will be use and from the experimental date, the shape of the two first modes will be reconstructed.

\section{Methods and Material}

Two different manners to have a bending effect by heating the CBCM have been identified: one called "single effect" or "temperature effect", another called "double effect" or "gradient effect". The characterization between "single" or "double" is a reference to the possibility for CBCM plates to bend in one or two directions. The different coefficients can be obtained either by different materials or by different orientations of the reinforcement in the layers. The result is, as previously shown, the bending of the plate below figure. 
Temperature effect

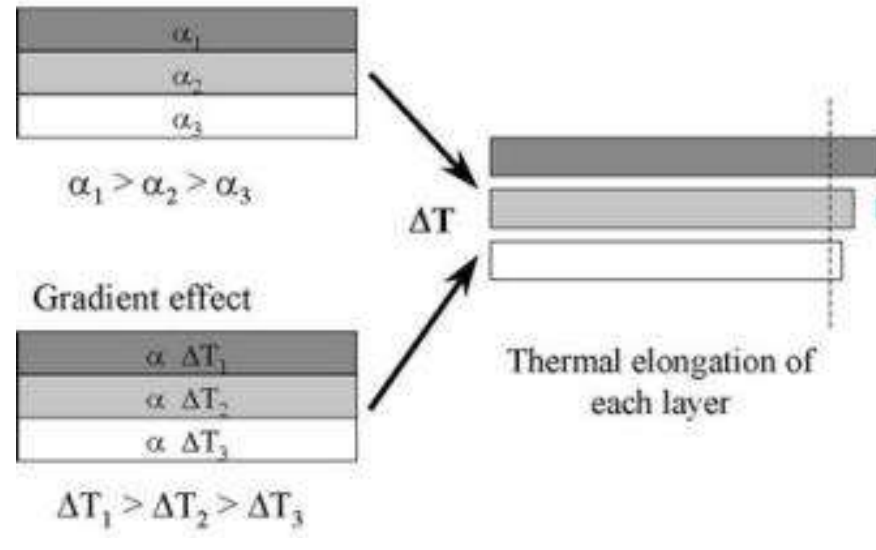

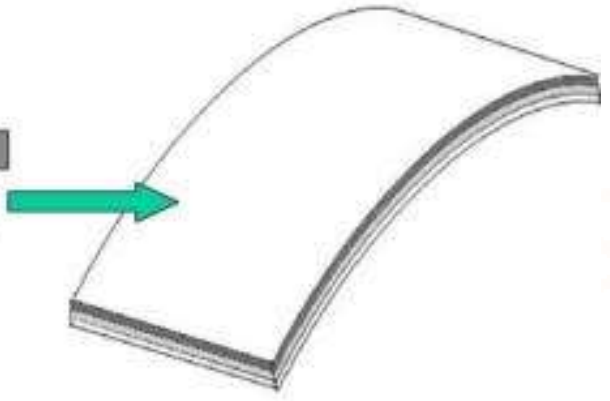

Perfect adhesion between layers : the structure bends

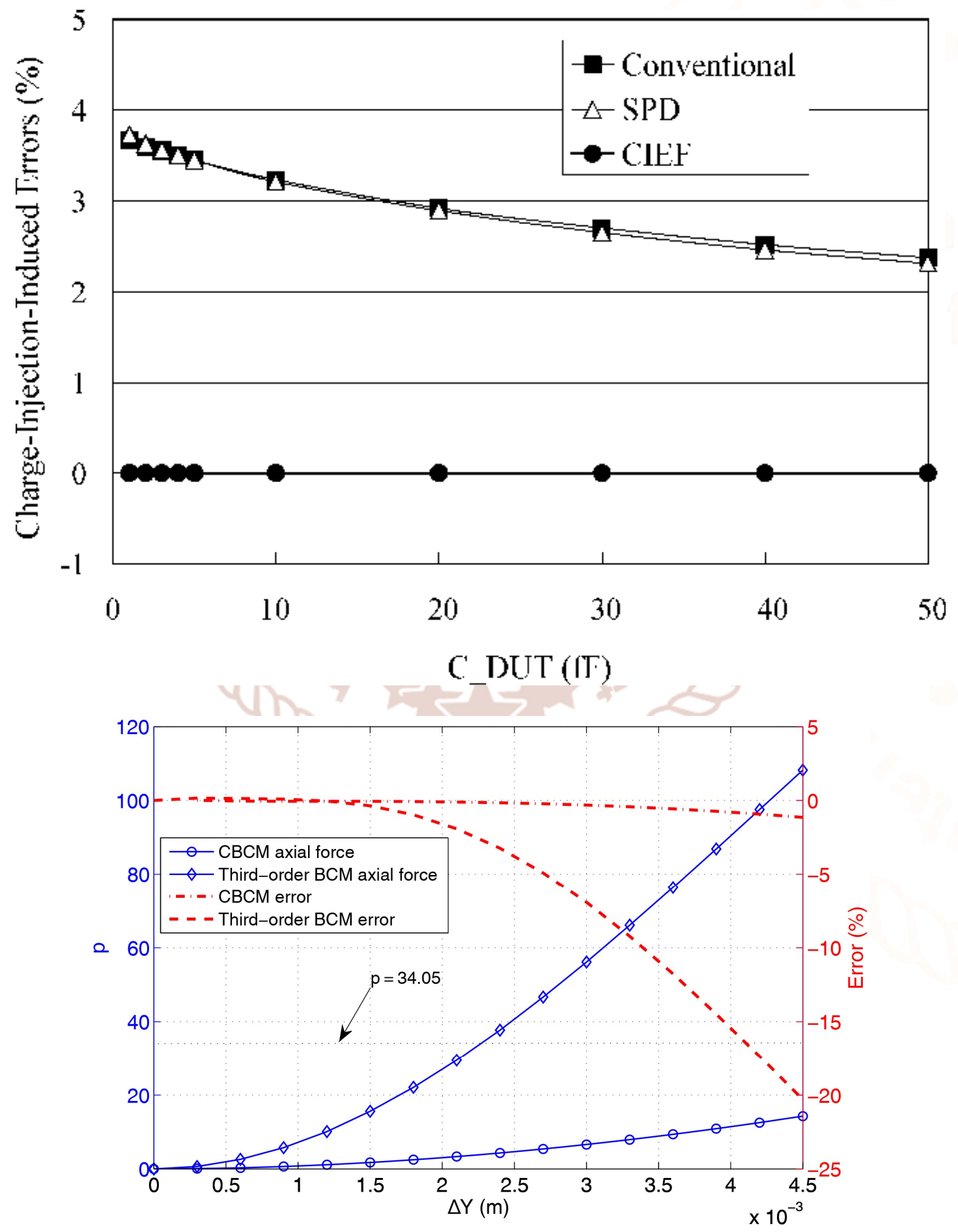


Two kinds of boundary conditions are considered: free/free and embedded/embedded. To perform the dynamic analysis, the measuring systems is composed by a Brüel \& Kjær acquisition system, an impact hammer (stress sensor PCB 086C05 \# 13381), a piezoelectric accelerometer (Brüel \& Kjaer 4393\# 1803841, sensitivity $0319 \mathrm{pC} / \mathrm{ms}^{-2}$ ), an amplifier (Endevco 133 \# BD69, gain $10 \mathrm{mV} / \mathrm{ms}^{-2}$ ) and a Pulse acquisition module with $\mathrm{I} / \mathrm{O} 4 / 2$ way 3109 . For the value of a modal frequency, this set gives accuracy equal to $\pm 2 \mathrm{~Hz}$.

The second experimental procedure consists to highlight the influence of change of rigidity of the plates due to the mechanical softening of the matrix function due to the temperature increase. The plate is embedded on line $\mathrm{A}$ and $\mathrm{B}$ below figure. The measurement area $(240 \times 125 \mathrm{~mm} 2)$ is discretized in 20 measurement nodes. The dynamic analysis is performed using a system acquisition, Brüel \& Kjaer, an impact hammer (with force sensor PCB 086C05 \# 13381), a front acquisition Pulse (Controller Module 7539 A). The speed of the plate is measured using a laser vibroscope (Ometron DV-500-D) in the node 1 as the reference node. During the test, the 20 nodes are successively affected by the hammer. The modal frequency accuracy is equal to $0.2 \mathrm{~Hz}$. After treatment, in order to construct the shape of the different modes, experimental data are transferred to ME'scope VES software.

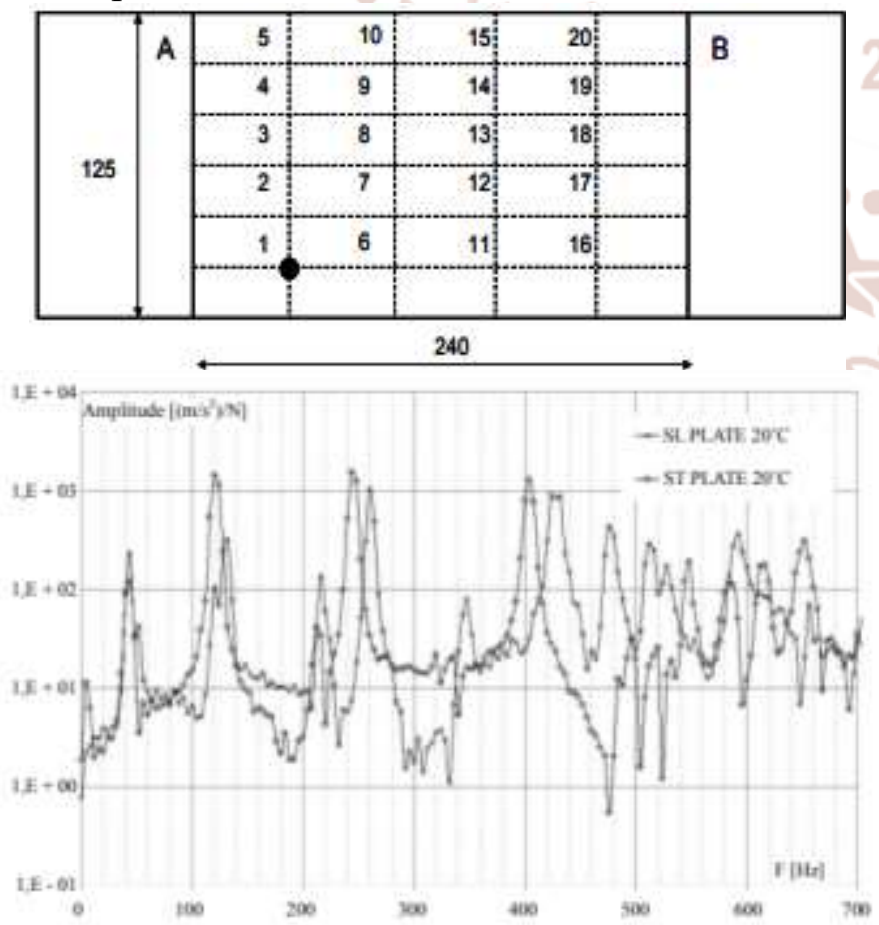

SL and ST plates dynamical response at $20^{\circ} \mathrm{C}$ (free/free boundary conditions) shown in above figure.
Frequency modal value for free-free boundary conditions $(\mathrm{Hz})$ shown in below table.

\begin{tabular}{ccccccc}
\hline & \multicolumn{3}{c}{$\mathrm{SL}$} & \multicolumn{3}{c}{ ST } \\
\hline Mode & $20^{\circ} \mathrm{C}$ & $100^{\circ} \mathrm{C}$ & $\delta(\%)$ & $20^{\circ} \mathrm{C}$ & $100^{\circ} \mathrm{C}$ & $\delta(\%)$ \\
1 & 44 & 44 & - & 4 & 6 & - \\
2 & 120 & 104 & 13 & 44 & 36 & 18 \\
3 & 132 & 128 & - & 120 & 120 & - \\
4 & 216 & 192 & 11 & 212 & 180 & 15 \\
5 & 260 & 232 & 11 & 244 & 236 & 3 \\
6 & 348 & 312 & 10 & 332 & 296 & 11 \\
7 & 428 & 416 & 3 & 404 & 388 & 4 \\
\hline
\end{tabular}

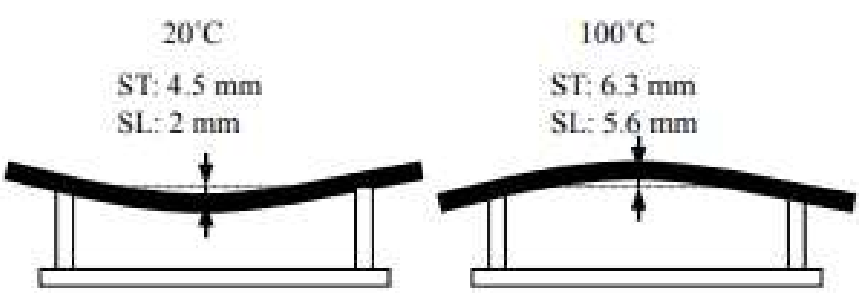

Curvature change for SL and ST plates shown in above figire.

Frequency modal value for embedded/embedded boundary conditions $(\mathrm{Hz})$ shown in below table.

\begin{tabular}{ccccccc}
\hline \multicolumn{3}{c}{ SL. } & & \multicolumn{3}{c}{ ST } \\
\hline Mode & $20^{\circ} \mathrm{C}$ & $100^{\circ} \mathrm{C}$ & $\delta(\%)$ & $20^{\circ} \mathrm{C}$ & $100^{\circ} \mathrm{C}$ & $\delta(\%)$ \\
1 & 32 & 32 & - & 32 & 32 & - \\
2 & 60 & 60 & - & 92 & 92 & - \\
3 & 108 & 104 & - & 128 & 112 & 13 \\
4 & 148 & 136 & 8 & 252 & 248 & - \\
5 & 292 & 284 & 3 & 304 & 276 & 9 \\
6 & 496 & 472 & 5 & 492 & 480 & 2 \\
7 & 648 & 604 & 7 & 660 & 604 & 8 \\
\hline
\end{tabular}

When the plate is heating three phenomena are in competition. The initial stress field and the stress field induce by the $\mathrm{CBCM}$ effect. Linking to the asymmetry of the composite, these fields are higher for the ST plate and lead to an increase in stiffness along the longitudinal direction of the plate. The third phenomenon is the loss of stiffness and for the ST plate, due to the orientation of the glass unidirectional; this phenomenon's effect is higher for the longitudinal direction. 


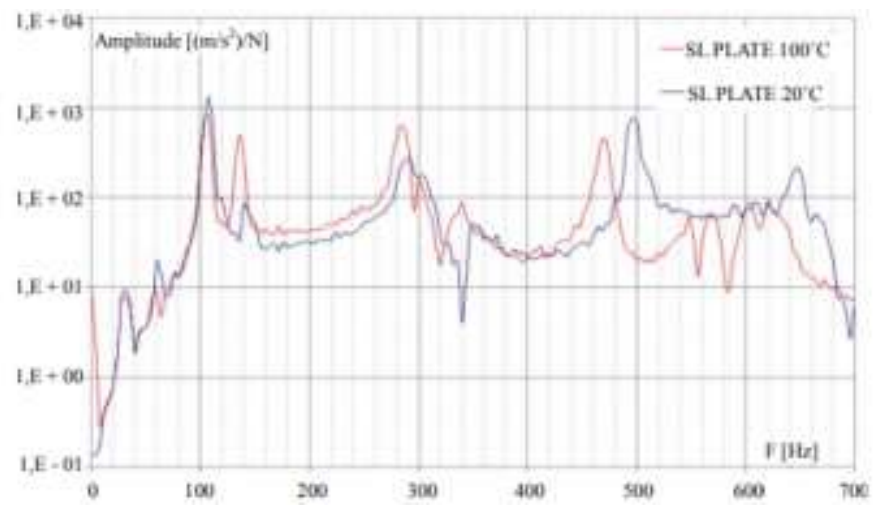

SL plate dynamical response (embedded/embedded boundary conditions)

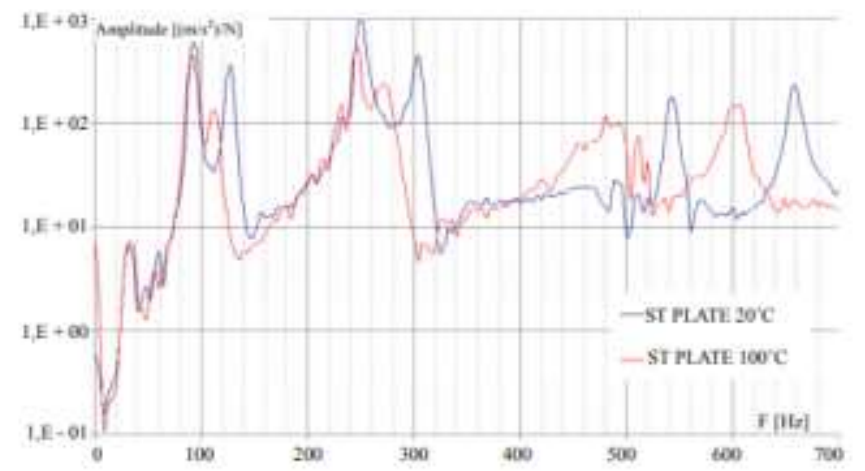

ST plate dynamical response (embedded/embedded boundary conditions)

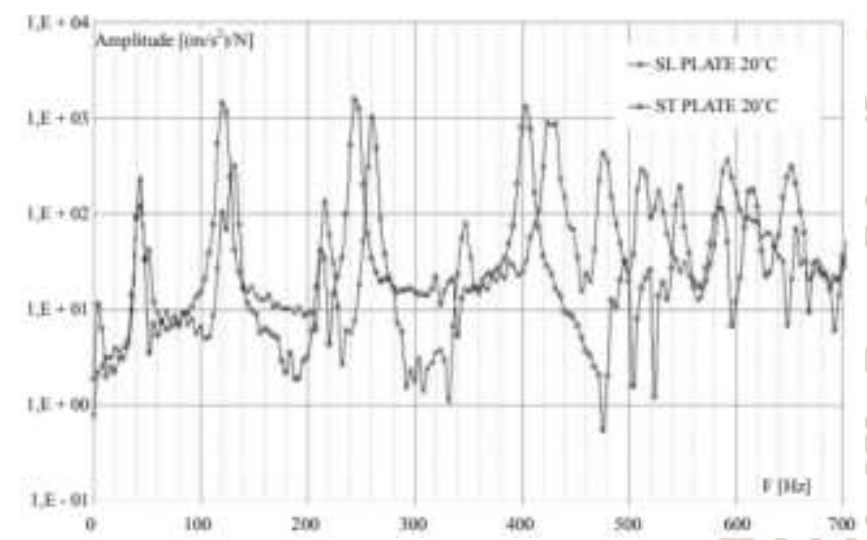

Dynamic response, SYM plate, embedded/embedded, at $20^{\circ} \mathrm{C}$ and $100^{\circ} \mathrm{C}$

\section{CONCLUSIONS}

This result has been also observed for inserted SMA, for their temperature of activation. The loss of rigidity of the matrix is accompanied by an increase in its viscous properties.
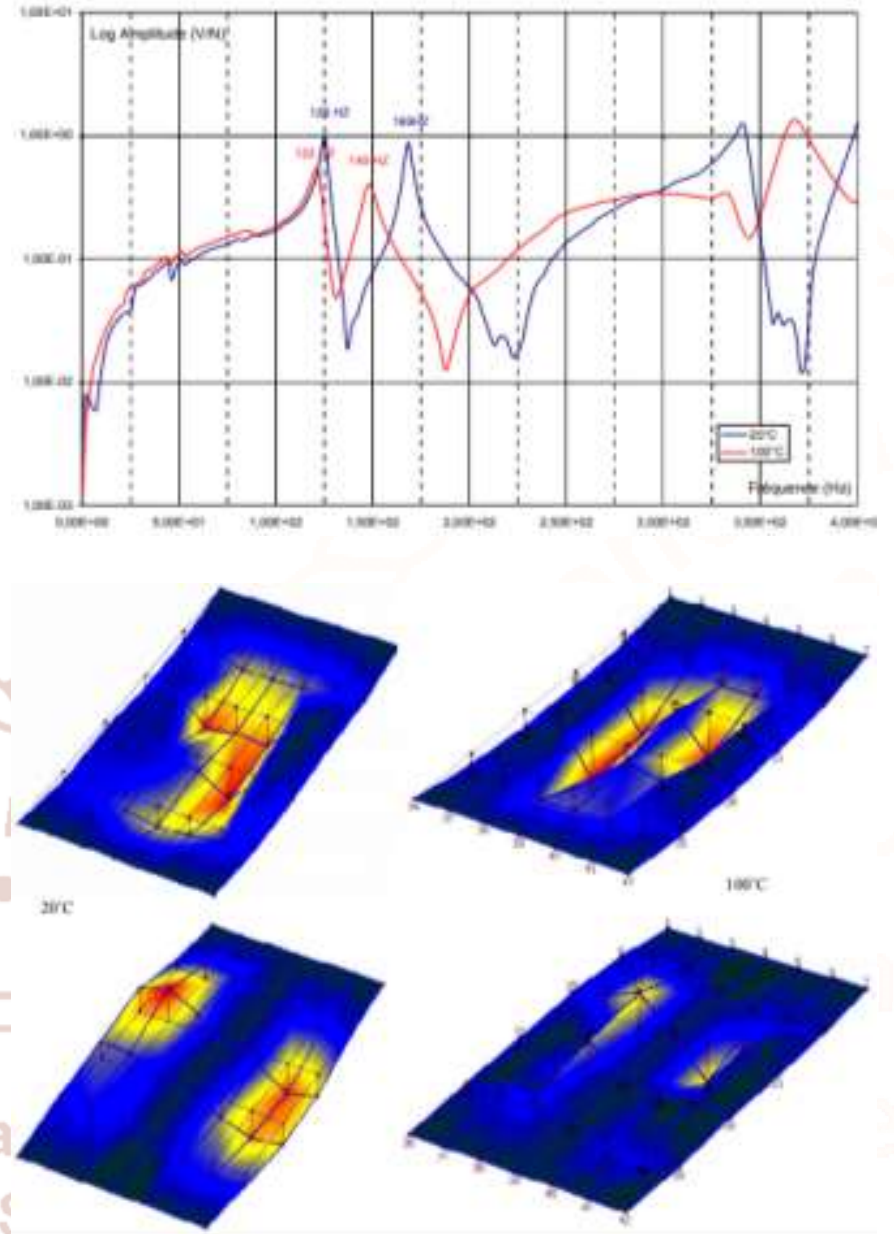

Modal shape, ST plate

Finally, one of the main advantage action compared to SMA or piezoelectric technologies is its simplicity of implementation in the process of composite structures manufacturing and this for any kinds of structure geometry.

\section{REFERENCES}

1. G. V. Kumar, S. Raja, K. B. Prasanna and V. Sudha, "Finite Element Analysis and Vibration Control of a Deep Composite Cylindrical Shell Using MFC Actuators," Smart Materials Research, Vol. 2012, 2012, Article ID: 513271.

2. K. Yuse and Y. Kikushima, "Development and Experimental Consideration of SMA/CFRP Actuator for Vibration Control," Sensors and Actuators A, Vol. 122, No. 1, 2005, pp. 99-107. doi:10.1016/j.sna.2005.03.057

3. D. M. Elzey, A. Y. N. Sofla and H. N. G. Wadley A Shape Memory-Based Multifunctional Structural Actuator Panel," International Journal of solids and Structures, Vol. 42, No. 7, 2005, pp. 1943-1955. 
4. M. V. Donadon, S. F. M. Almeida and A. R. de Faria, "Stiffening Effects on the Natural Frequencies of Laminated Plates with Piezoelectric Actuators," Composite Part B, Vol. 33, No. 5, 2002, pp. 335-342.
5. M. R. Schultz, M. W. Hyer, R. B. Williams, W. K. Wilkie and D. J. Inmann, "Snap-Through of Unsymmetric Laminates Using Piezocomposite Actuators," Composites Science and Technology, Vol. 66, No. 14, 2006, pp. 2442- 2448

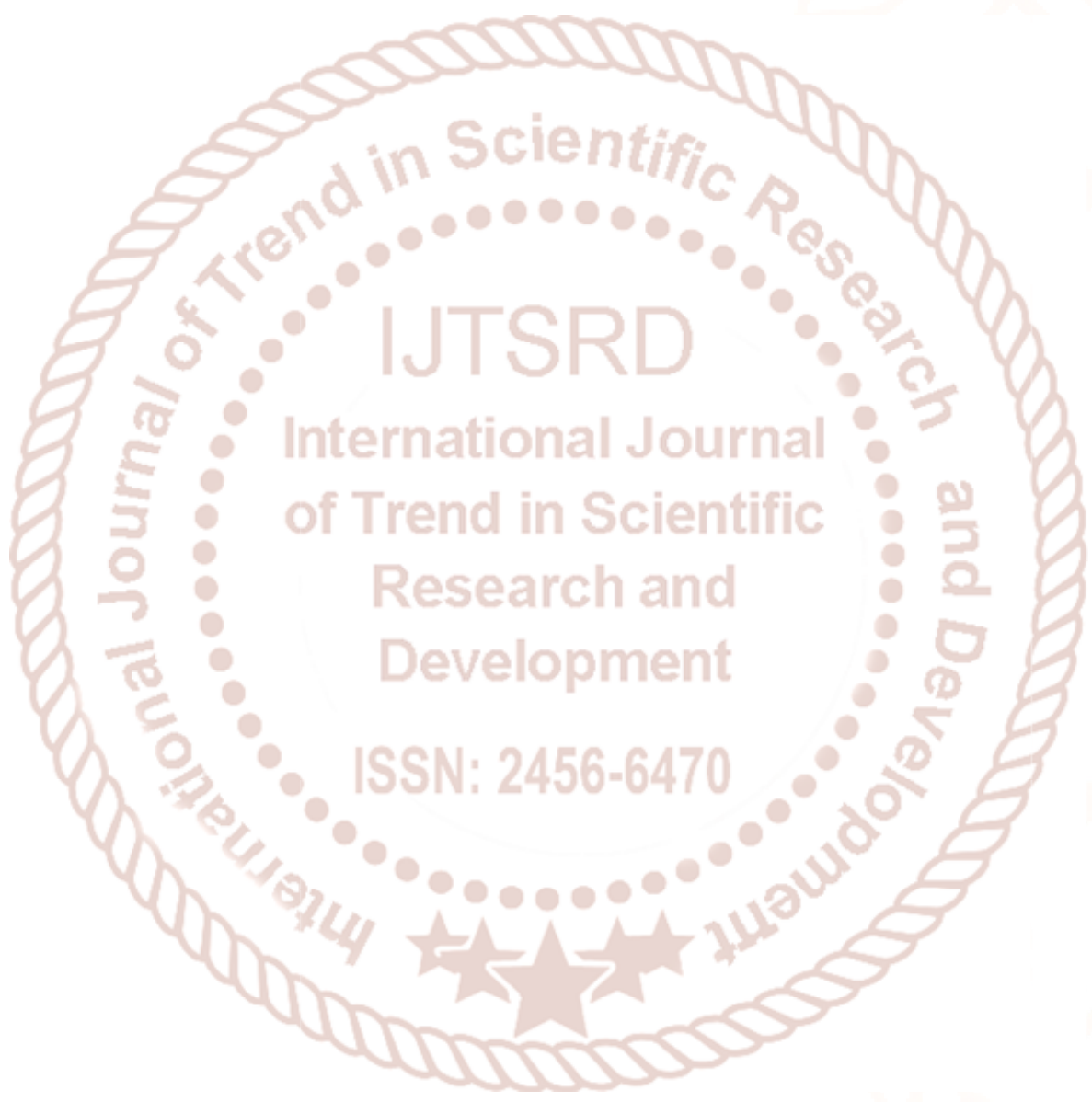

